\title{
Additions and Corrections
}

\section{Potentiometric Determination of L-Ascorbic Acid in Pharmaceutical Samples by FIA Using a Modified Tubular Electrode}

Julio Cesar B. Fernandes, Laércio Rover Jr., Lauro T. Kubota and

Graciliano de Oliveira Neto - 2000, vol. 11. No. 2, 182-186.

Figure 1 should be interchanged with Figure 2, keeping the original captions. The unit $\mathrm{mL}$ should be replaced by $\mu \mathrm{L}$ on p. $183(500 \mu \mathrm{L}, 500 \mu \mathrm{L}$ and $100 \mu \mathrm{L})$, on p. 184 $(100 \mu \mathrm{L}$ and $50 \mu \mathrm{L})$, and in the captions of Figures 3 and 4 . Equation 7 (p. 185), should be:

$\Delta \mathrm{E}=-(212 \pm 6)+(69 \pm 3) p[$ ascorbic acid $]$ 